\title{
Proposal Model for relating the Risk Analysis in the context of the Product Life Cycle
}

\author{
Philip De Simone*, Robert Eduardo Cooper Ordoñez
}

\begin{abstract}
After bibliographic research on data bases about Risk Analysis it was concluded that current methods for risk analysis in projects are very complicated and depend on previous data of companies, making it difficult and may even prevent applications in small enterprises. The Risk Impact Method was a model developed to analyze the risks and delays of a schedule over its execution simply and easily, to facilitate its application in small enterprises. Through the calculation of the risk impacts, the influence of delays encountered during the project can be evaluated so that actions can be taken quickly and the total delay of the project diminished.
\end{abstract}

\section{Key words:}

Project Management, Risk Analysis, Risk Impact.

\section{Introduction}

The Risk Analysis has proved to be a crucial step for the success of a project, however the existing methodologies hinder the application in various companies, mainly the smaller ones. The methods, in most cases, require statistical basis of the company and dedicated people to the subject, which can prevent their applications. Therefore, it is proposed to develop a simple and easy method of tracking any project schedule based on the analysis of the risks to indicate if the project manager should or should not act with respect to the delay identified to minimize the total delay of the project.

\section{Results and Discussion}

To define what are the possible risks that can be found throughout a project, a bibliographic research was made to define the risk variables in projects and they were selected from the article from Yim et al. ${ }^{1}$. The five variables selected are: related to external environment (RTE), organization (RTO), high level management performance (RMP), functional manager and team (PMT) and to the project characteristics (RTP).

After identified the variables a questionnaire was elaborate and sent to project managers in Brazil to identify and validate the impact of each variables. There were also conducted two pilot tests with the Risk Impact Method to develop the most complete model.

The model does not use statistical data for decision making, but an equation that will bring a result that should be compared with a measurement range (not set yet). The tool is associated with the $\mathrm{PMBoK}^{2}$ through the Monitoring and Control stage, basically with impact in time (schedule). The advantage of this is that the steps Identification and Risk Planning can be maintained within the standards already used in each company.

The Risk Impact Method will be presented bellow in five steps:

1. Risk Analysis: Assign weights from 1 to $2(1,1.25$, $1.5,1.75$ or 2 ) to the five variables.

\section{Elaborate the project schedule}

3. Start of the project

4. Monitoring the schedule: from the calculation of the Impacts of the risks when there is a delay in an activity. Impact calculation:

$\operatorname{Impact}(i)=\operatorname{delay}(i) \times \frac{p t}{t t} \times S S \times \operatorname{weight}(i)$
- $\operatorname{delay}(i)=$ is the number of days needed to finish the activity;

- $p t=$ project time;

- $t t=$ the total time;

- $S S=$ Student Syndrome component (consideration of the procrastination by people to perform any activity);

- weight $=$ assignment due to the influence of each variable based on previous experiences.

5. Impact assessment: assess whether the Impact value calculated is critical or not.

Image 1 shows an application of the method performed for one of the pilot tests. The project monitored by the Risk Impact Method showed a smaller factor, verified through a shorter delay of completion time of the project.

Image 1. Comparison between projects with and without method.
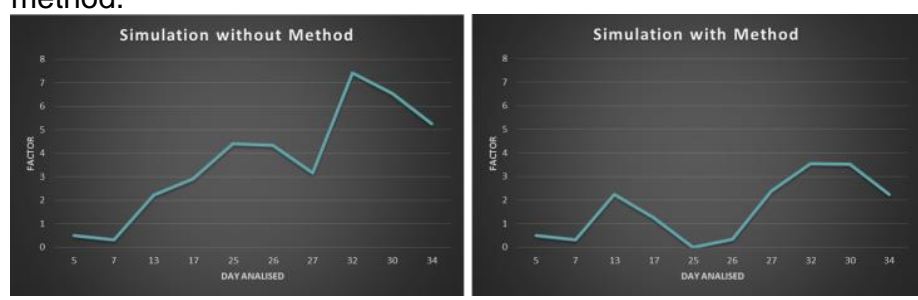

\section{Conclusions}

With the proposed method, it will be possible to analyze the impacts of the delays of a project and take corrective action throughout its execution to increase the probability of finishing it on time and not to only analyze when the project has already been completed. Thus, the interface suits as a simple assessment tool to determine if corrective actions should be taken or not.

\section{Acknowledgement}

This project was funded by $C N P q$ through the Institutional Scientific Initiation Scholarship Program (PIBIC), being supported by PRP (Pró-Reitoria de Pesquisa) of the University of Campinas (UNICAMP).

1 YIM, R.; CASTANEDA, J.; DOOLEN, T.; TUMER, I.; MALAK, R. A study of the impact of project classification on project risk indicators. International Journal of Project Management, p. 863-876, 2015.

2 PROJECT MANAGEMENT INSTITUTE. A Guide to the Project Management Body of Knowledge (PMBOK® Guide), 5 ed., Newton

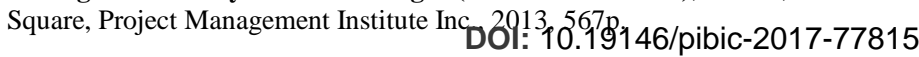
XXV Congresso de Iniciação Científica da UNICAMP 